\title{
BMJ Open Barriers to follow-up after an abnormal cervical cancer screening result and the role of male partners: a qualitative study
}

John Chapola (1) , ${ }^{1}$ Fan Lee, ${ }^{2}$ Agatha Bula, ${ }^{3}$ Clement Mapanje, ${ }^{4}$ Billy Rodwell Phiri, ${ }^{3}$ Nenani Kamtuwange, ${ }^{3}$ Mercy Tsidya, ${ }^{5}$ Jennifer H Tang (1) , ${ }^{6,7}$ Lameck Chinula ${ }^{4}$

To cite: Chapola J, Lee F, Bula A, et al. Barriers to followup after an abnormal cervical cancer screening result and the role of male partners: a qualitative study. BMJ Open 2021;11:e049901. doi:10.1136/ bmjopen-2021-049901

- Prepublication history for this paper is available online. To view these files, please visit the journal online (http://dx.doi org/10.1136/bmjopen-2021049901).

Received 07 February 2021 Accepted 03 September 2021

Check for updates

(c) Author(s) (or their employer(s)) 2021. Re-use permitted under CC BY-NC. No commercial re-use. See rights and permissions. Published by BMJ.

For numbered affiliations see end of article.

Correspondence to

Mr John Chapola;

johnchapola@gmail.com

\section{ABSTRACT}

Introduction Cervical cancer is the leading cause of cancer deaths among women in Malawi, but preventable through screening. Malawi primarily uses visual inspection with acetic acid (VIA) for screening, however, a follow-up for positive screening results remains a major barrier, in rural areas. We interviewed women who underwent a community-based screen-and-treat campaign that offered same-day treatment with thermocoagulation, a heat-based ablative procedure for VIA-positive lesions, to understand the barriers in accessing post-treatment follow-up and the role of male partners in contributing to, or overcoming these barriers.

Methods We conducted in-depths interviews with 17 women recruited in a pilot study that evaluated the safety and acceptability of community-based screen-andtreat programme using VIA and thermocoagulation for cervical cancer prevention in rural Lilongwe, Malawi. Ten of the women interviewed presented for post-treatment follow-up at the healthcare facility and seven did not. The interviews were analysed for thematic content surrounding barriers for attending for follow-up and role of male partners in screening

Results Transportation was identified as a major barrier to post-thermocoagulation follow-up appointment, given long distances to the healthcare facility. Male partners were perceived as both a barrier for some, that is, not supportive of 6 -week post-thermocoagulation abstinence recommendation, and as an important source of support for others, that is, encouraging follow-up attendance, providing emotional support to maintaining post-treatment abstinence and as a resource in overcoming transportation barriers. Regardless, the majority of women desired more male partner involvement in cervical cancer screening. Conclusion Despite access to same-day treatment, long travel distances to health facilities for post-treatment follow-up visits remained a major barrier for women in rural Lilongwe. Male partners were identified both as a barrier to, and an important source of support for accessing and completing the screen-and-treat programme. To successfully eliminate cervical cancer in Malawi, it is imperative to understand the day-to-day barriers women face in accessing preventative care.

\section{INTRODUCTION}

Cervical cancer is preventable if precancerous lesions are detected early and adequately

\section{Strengths and limitations of this study}

- We interviewed women who completed the entire screen-and-treat programme, including posttreatment follow-up, to understand their experiences and challenges with the programme.

- We interviewed seven participants who did not make their post-thermocoagulation follow-up appointments to understand realistic barriers that prevented follow-up completion.

- We had an experienced qualitative interviewer (MT) who conducted extensive hour-long interviews that allowed participants to reflect and discuss their experiences freely and in-depth.

- Selection bias is a limitation to our study as we only interviewed women who presented for screening and underwent thermocoagulation for an abnormal visual inspection with acetic acid result.

- We only interviewed participants, but not their male partners.

treated. However, cervical cancer remains the fourth most common cancer among women globally, disproportionately affecting low-income and middle-income countries (LMICs) where HIV burden is high and screening rates are low. ${ }^{1}$ Malawi, a country in sub-Saharan Africa (SSA) has the highest cervical cancer incidence and mortality in the world, with an age-standardised rate of 72.9 and 54.5 per 100000 women per year, respectively. ${ }^{2}$ In 2019 alone, 4163 new cases of cervical cancer were diagnosed in Malawi and 2879 women died from this disease. ${ }^{3}$

In efforts to fight this deadly disease, in 2004, Malawi implemented the single-visit screen-and-treat strategy for secondary prevention of cervical cancer, using visual inspection with acetic acid (VIA) to detect precancerous lesions and same-day cryotherapy to treat VIA-positive lesions amenable for ablative therapy. ${ }^{4}$ VIA is a visual examination of the uterine cervix after application of $3 \%-5 \%$ acetic acid to detected abnormal cells that could develop into cervical cancer 
if untreated. ${ }^{3}$ Cryotherapy is an ablative procedure that destroys precancerous lesions identified on VIA through freezing. While screening age was from 25 to 65 years old, the programme targeted women aged $30-45$ years and women on HIV Antiretroviral Therapy (ART). ${ }^{5}$ HIV negative women were screened once every 5 years while women living with HIV were screened once every 2-3 years. ${ }^{5}$ However, an evaluation of the programme between 2011 and 2015 revealed that screening rates remained low at $26.5 \%$ and most VIA-positive women eligible for cryotherapy, never received treatment. ${ }^{5}$ The high running cost of sustaining cryotherapy machines left machines non-functional, and therefore same-day treatment was often not available and percentage of patients who returned for treatment was low. On the other hand, reasons for low screening uptake are multifactorial. Studies from SSA have shown psychosocial barriers such as stigma of disease and decision-making barriers related to patriarchal systems, as major contributors to nonparticipation in screening. ${ }^{6-8}$ Geographical limitations to access has also been shown. ${ }^{9}$ In a predominantly rural country of Malawi, with $83 \%$ rural population, ${ }^{10}$ long travel distances to healthcare facilities and prohibitive costs of transportation are thought to be major barriers to accessing screen-and-treat services and attending posttreatment follow-up care.

To address some of these barriers, we implemented a pilot campaign to bring cervical cancer screen-and-treat services directly into rural communities. We also used thermocoagulation, instead of cryotherapy, to treat VIApositive lesions. Thermocoagulation is an ablative procedure with efficacy comparable to that of cryotherapy but uses portable devices and requires less resources to run sustainably. ${ }^{11-13}$ Along with assessing uptake of the services, the study aimed at exploring the experiences of women who underwent VIA and thermocoagulation as well as post-treatment barriers, including barriers to follow-up care and the role of male partners in screening and post-treatment process.

\section{METHODS}

\section{Study site and population}

University of North Carolina (UNC) Project-Malawi is a biomedical research institution located in Lilongwe within Kamuzu Central Hospital (KCH) premises and a collaboration between UNC Chapel Hill, Malawi Ministry of Health and KCH. In 2017, we implemented a community-based cervical cancer screen-and-treat pilot campaign that brought VIA screening and same-day thermocoagulation treatment to four rural communities in Lilongwe, Malawi. The four rural communities are located outside Lilongwe city, Traditional Authority Malili about $30 \mathrm{~km}$ and about 1-hour travel from most participants' homes to the follow-up care centre. The four communities were about $4 \mathrm{~km}$ and about $30-45 \mathrm{~min}$ travel from each other. The commonly used means of transportation are bicycle taxi, motorbike taxi and minivans. After permission was obtained from traditional leaders in each respective community, we conducted educational talks about cervical cancer prevention through community meetings and invited women to access the services. We also used a public address system using a vehicle in the community. On the day of screening, women who presented were screened for eligibility. ${ }^{14}$ Briefly, study population comprised of women between 25 and 49 years of age who had not had VIA screening in the last year, without history of hysterectomy, cervical surgery or genital cancer/precancer, and were not currently pregnant or within 12 weeks post partum. ${ }^{15}$ We enrolled women who had the ability and willingness to provide written informed consent.

Demographic information was collected and VIA screening with same-day thermocoagulation treatment for VIA positive lesions were provided. Women with larger lesions or suspected cancer were referred to $\mathrm{KCH}$ for follow-up. Women who received thermocoagulation were scheduled for 6-week and 12-week follow-up visit at UNC Project- Malawi study clinics located at KCH. Participants were required to travel to $\mathrm{KCH}$ on their own and reimbursed for travel costs on completion of the study visit.

Recruitment for the qualitative substudy took place at participants' 12-week follow-up visit. For those participants who did not present to their scheduled visit, community educators contacted the participants through phone or physical tracing to reschedule their missed follow-up visit. We aimed to interview both participants who attended their initial scheduled follow-up visit and those who missed their initial scheduled follow-up, therefore, required tracing and rescheduling. We estimated theme saturation at 10 interviews for each group. We estimated that through observation and analysis, there would be no new themes after 10 interviews in each group.

\section{Data collection and analysis}

Individual in-depth interviews took place in private designated research clinic rooms at UNC Project-Malawi. Interviews were conducted by an experienced qualitative interviewer (MT) in Chichewa, the local language. The semistructured interviews were guided by seven domains of inquiry: (1) baseline knowledge of cervical cancer; (2) perception of cervical cancer screening; (3) screen-andtreat experience; (4) acceptability of pilot screen-and-treat programme; (5) follow-up barriers; (6) community and partner support and (7) attitudes towards self-sampling for Human Papillomavirus (HPV) testing as alternative primary screening method. The interviews were audiotaped, translated and transcribed into English. Transcriptions were reviewed after each interview by study staff allowing for modification to interview guides as needed to explore new subthemes and ideas that emerged.

Content analysis was used to analyse the data. The transcripts were read by analysis team until the content was intimately familiar. A list of codes was generated based on identified themes from transcripts and structural codes that corresponded to initial interview questions. An iterative coding process between three coders (JC, FL and $\mathrm{AB}$ ) was conducted in NVivo V.12 until agreement was 


\begin{tabular}{|c|c|}
\hline Characteristics & $\mathrm{N}=17$ \\
\hline Median age (range) in years & $37(26-50)$ \\
\hline \multicolumn{2}{|l|}{ Age by decades } \\
\hline 20 s & 2 \\
\hline $30 \mathrm{~s}$ & 8 \\
\hline $40 \mathrm{~s}$ & 6 \\
\hline $50 s$ & 1 \\
\hline \multicolumn{2}{|l|}{ Level of education } \\
\hline No formal & 4 \\
\hline Some primary & 6 \\
\hline Completed primary & 5 \\
\hline Some secondary & 2 \\
\hline \multicolumn{2}{|l|}{ Marital status } \\
\hline Married monogamous & 11 \\
\hline Married polygamous & 4 \\
\hline Other & 2 \\
\hline \multicolumn{2}{|c|}{ Partners with additional partners } \\
\hline Yes & 11 \\
\hline No & 2 \\
\hline Unknown & 4 \\
\hline \multicolumn{2}{|l|}{ Total lifetime partners } \\
\hline 1 partner & 6 \\
\hline 2-3 partners & 10 \\
\hline$\geq 4$ partners & 1 \\
\hline
\end{tabular}

reached and a codebook was finalised. Coding comparisons were made and coding differences were discussed until an agreement was reached. To ensure intercoder reliability, $24 \%$ of data was coded by all three coders and the remainder of the transcripts were each double coded. The intercoder reliability was above $95 \%$. In this paper, we present the results of domains 5 and 6 , follow-up barriers and role of male partners.

\section{Patient and public involvement}

No patient involved.

\section{RESULTS}

Between July and August 2017, we screened 408women, 30 were VIA positive, of whom 28 were eligible for thermocoagulation and received treatment. Ten of the 28 participants failed to present to their scheduled post-treatment follow-up appointment, of whom 7 were successfully traced and accepted the interview. We, therefore, interviewed a total of 17 women who received thermocoagulation: 10 who presented for their follow-up visit and 7 who required tracing to complete follow-up. Data saturation had been reached after 17 interviews.

\section{Demographic characteristics}

The baseline demographic characteristic of the 17 participants are described in table 1 . The median age was 37 years old. Most were in 30 s and 40s age groups. The highest education completed was some secondary (two participants), while most had either some or completed primary education. Most were married in monogamous relationships (11 participants), however, most also reported that their partners likely had other partners. Most had 2-3 lifetime partners. All were HIV negative.

Barriers to presenting for follow-up for the seven participants that missed their initial scheduled follow-up visit

While the screen-and-treat campaign took place in the rural communities, post-thermocoagulation follow-up took place at UNC Project-Malawi, at $\mathrm{KCH}$, which was about $30 \mathrm{~km}$ and about 1-hour travel from most participants' homes. While participants were reimbursed for travel costs to the research clinic after completion of the visits, of the seven participants that did not make the initial scheduled follow-up appointment and were interviewed, many cited lack of or high cost of transportation as the major reason for not presenting for follow-up. Even those who successfully attended follow-up described the difficulty of travel, not being able to afford fuel for the motor bike and the fatigue of having to journey by foot. Other barriers that prevented participants from attending follow-up included illness or having to take care of family members who were ill, household duties and misunderstanding of where to follow-up (table 2). Participants also cited transportation as a likely reason for nonparticipation in screening services among other women in their communities. Furthermore, many participants requested that transportation be included in screen-andtreat programmes for those who have to travel to healthcare facilities for follow-up, referrals or further treatment.

\section{Role of male partners}

All 17 women were asked about the role of male partners to attending cervical cancer screening and follow-up. Male partners were perceived as both a barrier and as an important source of support by different participants.

Male partners as a barrier to attending screening or follow-up There was agreement among participants that lack of male partner support could be a major barrier for women in their communities to attend screening in general. One participant reported:

Not giving his wife transport can make the woman fail... there are some men who forbid their wives to go to the hospital for their own known reasons. (ID\#269, age 26)

Another participant described men's concern with their wives' privacy during screening:

Sometimes some males can discourage their women to go for screening because of jealousy, because there is undressing involved. (ID\#240, age 36)

There were also patriarchal themes highlighted by some participants as barriers. Specific barriers participants faced from their male partners included suspicion 
Table 2 Barriers to presenting for follow-up reported by participants who missed follow-up appointment ( $n=7$ )

\begin{tabular}{|c|c|c|}
\hline Participant and age & Reason for missing follow-up appointment & Quote \\
\hline ID\#116 age 33 & Recovering from Malaria and her child's illness & 'I failed to come because as I said earlier on, I had malaria.' \\
\hline $\begin{array}{l}\text { ID\#180 } \\
\text { age } 31\end{array}$ & $\begin{array}{l}\text { Sick child, no transport, busy in garden, } \\
\text { husband was on leave }\end{array}$ & $\begin{array}{l}\text { 'So, on the date when they said I should go, I failed because one of my children was sick } \\
\text { and I did not make it to the hospital.' }\end{array}$ \\
\hline ID\#207 age 32 & $\begin{array}{l}\text { Meeting/coordination misunderstanding, lack of } \\
\text { transportation, mother was sick }\end{array}$ & $\begin{array}{l}\text { 'I did not manage to come as I went for a very important meeting at Malili.... my in- } \\
\text { law was sick and admitted at KCH because she had a stroke, it was not possible for } \\
\text { me to come on that day. I came on another day and I was told that 'if you missed your } \\
\text { appointment then you cannot be helped as the doctors are not available', so I went back } \\
\text { and I never went there again.' }\end{array}$ \\
\hline ID\#329 age 41 & $\begin{array}{l}\text { Partner denied support and did not provide } \\
\text { transportation }\end{array}$ & $\begin{array}{l}\text { 'When I went home, I explained to my husband but we did not seem to agree on what to } \\
\text { do ... whenever I asked for transport, he used to refuse and say 'there is something you } \\
\text { want to do there and not for the medication' so it was hard for me to come.' }\end{array}$ \\
\hline
\end{tabular}

towards screening and refusal to provide money or transport to attend follow-up visits.

One participant reported that she relied on her partner for travel support:

The assistance I need [from my husband] is just transportation to get here to the clinic... the challenge is often the money to buy fuel to put in the motor bike to travel to the clinic.

(ID\#253 (Missed initial follow-up visit), age 48)

Another participant discussed how her male partner limited her ability to present for follow-up due to misunderstanding of the screening and treatment she received:

I was unable to come because we had misunderstandings with my husband, we were not on the same page...the condoms I was given for example, his conclusion was that I want to start prostitution...this time around however, he read the consent I was given and finished it. After he read it is when he now said let us go there together. (ID\#329*, age 41)

Apparent in this quote is stigma surrounding condom use and its association with prostitution. It also highlights the general lack of understanding surrounding cervical cancer prevention in the community. However, it also illustrates that the male partner was interested in learning more, as he read the consent and wanted to come along with his partner to her follow-up appointment so he could understand more.

Male partners as barriers in adherence to post-thermocoagulation instructions

Participants were counselled to abstain from vaginal sexual intercourse for 6 weeks after thermocoagulation to minimise risk of bleeding, infection and to allow the cervix to heal. This was a major challenge experienced by participants as it required disclosure and negotiation with their male partners. Some felt they were obligated to disclose their screening result and treatment procedure to their partners:

I had to inform him about my results, because I was also told to not have sex for sixweeks so he had to know (ID\#239, age 36)

Others reported that despite initially gaining support from their male partners, they were ultimately pressured into having sex before 6 weeks post-treatment:

They told me to wait for six weeks without having sex. After I told my husband he asked me to say is it possible for people who are married to stay for sixweeks without having sex; how is that even possible?' All I said was, that is what they told me. Then after 2 weeks I noticed that [chuckles] he was not going to manage. (ID329*, age 41)

The same participant suggested that giving women time to discuss with their partners before offering screening and treatment could help alleviate misunderstanding and pressure:

What you need to do when you want to conduct the screening is to tell people in advance when you are going to come, so as to give other women the chance of talking to their husbands about it. (ID\#207*, age 32).

\section{Male partners as source of support}

Other participants reported that they felt comfortable sharing their screening experience and screening results with their male partners. This participant only told her husband after a positive VIA and not only received encouragement to present for follow-up but was accompanied by her husband to the visit:

When I was found with the cancer cells, I told my partner that I went for cervical cancer screening and I have been 
found with cancer cells. I told him what happened and he said 'Go there, this is a fatal disease, and we are lucky that they have found it at this earlier stage when it can be treated. It could be difficult for us if you were very sick.' We came together here, and he is outside there. (ID\#351*, age 49)

In fact, several participants reported that their male partners attended the follow-up visits with them:

My husband and we come together just as you can see. He is happy that doctors came and found me with the disease which is a rare thing...He thinks it is important that we should be coming to the hospital to get help as long as we survive. (ID\#233, age 40)

Some male partners showed understanding of the concept of screening to catch a disease while it is still treatable, encouraging screening behaviour:

He says that the health workers have done well to come to our community because they have revealed the hidden disease. If we had waited till when I started showing signs of the disease it would have been impossible to get healed. (ID\#269, age 26)

Overall, most participants who managed to attend the follow-up visit reported some level of male partner support that helped them attend the follow-up visit, and all participants expressed that male partner support could assist in cervical cancer prevention.

\section{Male partner involvement in cervical cancer prevention}

When asked if male partners should be more involved in cervical cancer secondary prevention, overwhelmingly all participants were supportive of that idea. Participants reported wanting male partners to understand and help keep their wives healthy, wanting help with paying for or obtaining transportation, wanting men to take responsibility and not be promiscuous themselves. One participant compared cervical cancer screening to family planning initiatives:

I think [male partners] should [be involved with cervical cancer screening], it is the same as family planning, even the government is encouraging the men to let their wives use family planning so that by the time they have another child, the first one will be grown enough. Mainly I think the problem is illiteracy or lack of knowledge, especially in the villages. That is why the health personnel nowadays are putting an emphasis on the men because they have a big role to play in the health of their women. It is the same with cervical cancer, the man is supposed to encourage his wife to go for screening. If the woman gets sick, it is the man who will struggle and it is him who will have to spend his money for her to get better. (ID\#385*, age 39)

This participant also felt that men should be educated and counselled on this topic so that they can be encouraging of cervical cancer screening-seeking behaviour and that screening is a good financial investment:
They need to be enlightened that cervical cancer is very dangerous and that what they need to do is to encourage their wives to go and get screened for cervical cancer. They need to be reminded that when a child or when the woman is sick, they are the ones who suffer in taking care of them. They end up using money which could have been used for something else in the process of making sure the women get better. So, in order to save their money, they should encourage their wives to go and get screened for cervical cancer. (ID\#385 ${ }^{*}$, age 39 )

All but two participants voiced that male partners should accompany women to screening and/or follow-up visits to help with transportation but also to be counselled together.

If he can be accompanying me to the hospital, he can be present when I am being screened for cancer, and we can be counselled together. In this way he can know what causes cervical cancer and how it can be prevented." (ID\#180*, age 31)

Of the two who did not agree, one participant did not comment further. The other reported that men should not be at the screening because they would not want male doctors:

Men should not be there because it was mostly male doctors who were screening us. Do you think a man would allow another man to do tests on his wife? (ID\#329*, age 41)

Some participants inquired if male partners can also be screened so that the burden can be shared and male partners would be more understanding and supportive:

I told [my husband] that it was just unfortunate that only women were being screened for cancer. I feel it could have been better if the men were also screened because they said that the viruses are transmitted to the woman from the man (ID\#207, age 32)

When asked how to best reach men, all participants felt strongly that healthcare providers play an active role in reaching out to men and providing the same counselling and encouragement for screening as participants themselves received:

I think it would have been better that when you come for screening... you encourage the women to take their husbands as well so that as you are teaching the women about cancer, the men should also hear that message. For them however, you would encourage them to take their wives for cancer screening. (ID\#385*, age 39 )

Other participants shared they would like healthcare workers to specifically counsel male partners on how to support women after thermocoagulation treatment.

They should be taking part on following the instruction about refraining from sex for a month... They should also know that they are required to give us the transport... You can explain to them for most of them have women in their homes so they should be able to understand the dangers involved. No man would want his wife to die and leave him with kids. (ID\#269, age 26) 
Some participants suggested reaching out to village chiefs to mobilise men to be educated:

...like going through the chiefs to mobilize men for you and have them sit down and teach them just like how you did with us. They should understand the problems associated with this disease (ID\# 245, age 30)

\section{Discussion}

Our findings showed that transportation was a major barrier to adherence in attending post-treatment follow-up appointments among women in our study. Furthermore, male partners were perceived as both a barrier for some and as an important source of support for others when completing the screen-and-treat programme. Therefore, creasing the improving the availability of transport and improving partner involvement in cervical cancer prevention and treatment may help improve cervical cancer screening and adherence to follow-up appointments among women with abnormal VIA results.

Despite addressing barriers of access by providing community-based screening and same-day treatment, participants still faced major hindrance with presenting for post-treatment follow-up. The overwhelming difficulty for women who missed their initial follow-up visits, requiring tracing and rescheduling, was the long-travel distance and prohibitive cost of transportation. Participants who did not miss their follow-up appointments, also reported similar barriers. This has been echoed in many studies of screening access in LMIC. ${ }^{16}$

The nature of post-thermocoagulation care requiring sexual abstinence and attending additional follow-up visits at healthcare facilities also inevitably posed barriers at home with male partners. Participants felt that they were put in positions to negotiate sexual abstinence for post-treatment and seek transportation money from their male partners to attend follow-up. These findings are similar to other studies in Malawi. ${ }^{17}$ The limited decisionmaking capacity of women regarding their own health in a patriarchal system poses difficulty for screening uptake and completion. In many Malawian societies, family decisions including health decisions, are spearheaded by male partners. ${ }^{18}$ If male partners have concerns about health procedures, they are often unwilling to provide moral support and financial assistance. ${ }^{19}$ For example, one participant described her partner's negative reaction to condoms. Stigma surrounding condoms is often associated with prostitution. ${ }^{20}$ It is unusual for women to be found with condoms, and the situation is often met by men with mixed reactions with most men associating condoms with promiscuity. ${ }^{21}$

Participants also expressed appreciation for support they received from male partners, especially encouragement and financial support for attending follow-up. Some men even accompanied their wives to the follow-up visit to learn more. This is consistent with studies that show increased screening uptake with male partner involvement. ${ }^{17}$ Furthermore, a lack of knowledge on cervical cancer prevention among men have potential negative influence on uptake of the services, particularly in relation to women receiving permission and financial assistance to undergo screening and treatment. ${ }^{22}$ It is evident from these findings that that male partners have potential to be a strong positive influence on women's health seeking behaviour. Therefore, it is not surprising that almost all participants expressed desire for more male partner involvement with cervical cancer screening and urged healthcare workers to play a more active role in educating and counselling men regarding the disease.

Future cervical cancer screen-and-treat campaigns should continue to address transportation barriers to access. This could include providing free or lowcost transportation to healthcare facilities or schedule follow-up visits to occur in the community. Male partner support can be harnessed for cervical cancer prevention and education of men on cervical cancer screen-andtreat methods should be prioritised in future campaigns to promote spousal support during the screening and treatment processes. While there is room for community leaders to encourage men involvement in cervical cancer prevention, per participants of this study, healthcare workers should take an active role in reaching out to men as well. ${ }^{16}$

A limitation of our study is that we gathered the opinions of the women who had abnormal VIA results and underwent same-day thermocoagulation treatment, which may have affected their perceptions and opinions about cervical cancer screening. This study does not capture the perspectives of male partners of women who did not participate in the screening, who had normal VIA results or those who were lost to follow-up. In addition, we did not interview their male partners to understand their perceptions towards some of the barriers and their role in women's health when it comes to cervical cancer prevention and treatment. However, interviewing women who required completion of the screen-and-treat algorithm and follow-up appointments allowed us to explore barriers with adherence to post-thermocoagulation instructions specifically need to abstain from sexual intercourse for 6 weeks and also with adherence to follow-up visit appointments. Nevertheless, further studies should include interviewing men to capture their knowledge about cervical cancer, particularly their opinions about how they feel about the recommendations after thermocoagulation and how that influences their decision to support women to present for follow-up visits at a referral health facility after abnormal VIA results.

\section{Author affiliations}

${ }^{1}$ Data, University of North Carolina Project, Lilongwe, Central Region, Malawi ${ }^{2}$ Obstetrics and Gynecology Department, University of North Carolina System, Chapel Hill, North Carolina, USA

${ }^{3}$ Nursing Department, University of North Carolina Project, Lilongwe, Central Region, Malawi

${ }^{4}$ Clinical Department, University of North Carolina Project, Lilongwe, Central Region, Malawi 
${ }^{5}$ Qualitative Department, University of North Carolina Project, Lilongwe, Central Region, Malawi

${ }^{6}$ University of North Carolina, Chapel Hill, North Carolina, USA

${ }^{7}$ University of North Carolina Project, Lilongwe, Central Region, Malawi

Acknowledgements We would like to thank the participants, the Lilongwe District Health Management Team including the Director of Health and Social Services, local community leaders, UNC Project Community Advisory Board, Reproductive Health Directorate of the Malawi Ministry of Health.

Contributors $\mathrm{JC}$ assisted with the design of this study, conducted the analysis and manuscript writing. $\mathrm{FL}$ and $\mathrm{AB}$ assisted with the design and implementation of this study, conducted analysis and assisted with manuscript writing. CM acted as study clinical officer, assisted with study implementation, patient care and data collection. BRP and NK were study nurses, assisted with study implementation, patient care and data collection. MT administered interviews and translated interviews from Chichewa to English. JT and LC designed the study and supervised the implementation of the study, the analysis and manuscript writing. All authors read and approved the final manuscript.

Funding This work was cofunded by National Institute of Health (NIH) U54CA190152 Malawi Cancer Consortium Grant and NIH Fogarty International Center Grant \#R25TW009340.

Disclaimer The study funders were not involved in the design, implementation, analysis or interpretation of this study.

Competing interests A portion of the findings of this study was presented as a poster presentation at the 22nd FIGO World Congress of Gynaecology \& Obstetrics in Rio de Janeiro, Brazil (14 October 2018-19 October 2018).

Patient and public involvement Patients and/or the public were not involved in the design, or conduct, or reporting, or dissemination plans of this research.

Patient consent for publication Not required.

Ethics approval The study protocol, the informed consent form, and study-related documents were reviewed and approved by the Malawi National Health Sciences Research Ethics Committee (NHSRC), (Approval number 1667) and UNC IRB (Approval number UNCPM 21607). Before beginning the study, approval was also sought from local authorities and the Lilongwe District Director of Health and Social Services.

Provenance and peer review Not commissioned; externally peer reviewed.

Data availability statement All data relevant to the study are included in the article or uploaded as online supplemental information. All data relevant to the study are included in the article or uploaded as online supplemental information and includes deidentified participant data.

Open access This is an open access article distributed in accordance with the Creative Commons Attribution Non Commercial (CC BY-NC 4.0) license, which permits others to distribute, remix, adapt, build upon this work non-commercially, and license their derivative works on different terms, provided the original work is properly cited, appropriate credit is given, any changes made indicated, and the use is non-commercial. See: http://creativecommons.org/licenses/by-nc/4.0/.

\section{ORCID iDs}

John Chapola http://orcid.org/0000-0002-6669-6499

Jennifer H Tang http://orcid.org/0000-0003-4238-2791

\section{REFERENCES}

1 Clifford GM, Franceschi S, Keiser O, et al. Immunodeficiency and the risk of cervical intraepithelial neoplasia $2 / 3$ and cervical cancer: a nested case-control study in the Swiss HIV cohort study. Int $J$ Cancer 2016;138:1732-40.

2 Cancer today. Available: http://gco.iarc.fr/today/home [Accessed 6 Jan 2021].
3 Comprehensive Visual Inspection of the Cervix with Acetic Acid (VIA) and Lugol's lodine (VILI). Available: https://www.gfmer.ch/ccdc/ victest.htm [Accessed $27 \mathrm{Jul}$ 2021].

4 World Health Organization. WHO guidelines for screening and treatment of precancerous lesions for cervical cancer prevention. Geneva: World Health Organization, 2013.

5 Msyamboza KP, Phiri T, Sichali W, et al. Cervical cancer screening uptake and challenges in Malawi from 2011 to 2015: retrospective cohort study. BMC Public Health 2016;16:806.

6 Teng FF, Mitchell SM, Sekikubo M, et al. Understanding the role of embarrassment in gynaecological screening: a qualitative study from the ASPIRE cervical cancer screening project in Uganda. BMJ Open 2014;4:e004783.

7 Nyambe A, Kampen JK, Baboo SK, et al. Knowledge, attitudes and practices of cervical cancer prevention among Zambian women and men. BMC Public Health 2019;19:508.

8 Ampofo AG, Adumatta AD, Owusu E, et al. A cross-sectional study of barriers to cervical cancer screening uptake in Ghana: an application of the health belief model. PLoS One 2020;15:e0231459.

9 Coleman JS, Cespedes MS, Cu-Uvin S, et al. An insight into cervical cancer screening and treatment capacity in sub Saharan Africa. $J$ Low Genit Tract Dis 2016;20:31-7.

10 Rural population (\% of total population) - Malawi | Data. Available: https://data.worldbank.org/indicator/SP.RUR.TOTL.ZS?locations= MW [Accessed 8 Jan 2021].

11 Dolman L, Sauvaget C, Muwonge R, et al. Meta-Analysis of the efficacy of cold coagulation as a treatment method for cervical intraepithelial neoplasia: a systematic review. BJOG 2014:121:929-42.

12 Sauvaget C, Muwonge R, Sankaranarayanan R. Meta-Analysis of the effectiveness of cryotherapy in the treatment of cervical intraepithelia neoplasia. Int J Gynaecol Obstet 2013;120:218-23.

13 Campbell C, Kafwafwa S, Brown H, et al. Use of thermo-coagulation as an alternative treatment modality in a 'screen-and-treat' programme of cervical screening in rural Malawi. Int $J$ Cancer 2016;139:908-15.

14 Chinula L. Uptake of a community-based screen-and-treat cervical cancer prevention strategy in rural Malawi. presented at the XXII FIGO WORLD CONGRESS of Gynecology \& Obstetrics, Rio de Janeiro, Brazil, 2018.

15 Chinula L, Topazian HM, Mapanje C, et al. Uptake and safety of community-based "screen-and-treat" with thermal ablation preventive therapy for cervical cancer prevention in rural Lilongwe, Malawi. Int J Cancer 2021;149:371-7.

16 Munthali AC, Ngwira BM, Taulo F. Exploring barriers to the delivery of cervical cancer screening and early treatment services in Malawi: some views from service providers. Patient Prefer Adherence 2015;9:501-8.

17 Moucheraud C, Kawale P, Kafwafwa S, et al. "It is big because it's ruining the lives of many people in Malawi": Women's attitudes and beliefs about cervical cancer. Prev Med Rep 2020;18:101093.

18 pp.Kumwenda M, Munthali A, Phiri M, et al. Factors shaping initial decision-making to Self-Test amongst cohabiting couples in urban Blantyre, Malawi. AIDS Behav 2014;18 Suppl 4:396-404.

19 Lewis S, Moucheraud C, Schechinger D, et al. "A loving man has a very huge responsibility": A mixed methods study of Malawian men's knowledge and beliefs about cervical cancer. BMC Public Health 2020:20:1494.

20 Shacham E, Thornton R, Godlonton S, et al. Geospatial analysis of condom availability and accessibility in urban Malawi. Int J STD AIDS 2016;27:44-50

21 Madiba S, Ngwenya N. Cultural practices, gender inequality and inconsistent condom use increase vulnerability to HIV infection: narratives from married and cohabiting women in rural communities in Mpumalanga Province, South Africa. Glob Health Action 2017;10:1341597.

22 Adewumi K, Oketch SY, Choi Y, et al. Female perspectives on male involvement in a human-papillomavirus-based cervical cancerscreening program in Western Kenya. BMC Womens Health 2019;19:107. 